\title{
Intraocular Lens Power Calculation
}

\author{
M. HOPE-ROSS and D. MOONEY \\ Dublin
}

\begin{abstract}
Summary
Accurate intraocular lens power calculation is an important adjunct to the technique of extracapsular cataract extraction. An increasing number of ophthalmologists now perform preoperative biometry routinely. We studied a group of fifty patients and analysed the accuracy of intraocular lens power calculation using the SRK ${ }^{\mathrm{TM}}$ formula.
\end{abstract}

In November 1949, Harold Ridley inserted the first intraocular lens. His patient's post operative refraction was $-12.00 \mathrm{DS}+6.0 \mathrm{DC}$ @30. He thus unwittingly ushered in the current era of intraocular lens power calculation.

Various methods can be used to determine intraocular lens power, namely previous spectacle correction, theoretical formulae and linear regression analysis. Alternatively, a lens of standard power can be implanted.

It has been suggested that if standard twenty dioptre lenses are used in patients who have a pre-operative refractive error of less than 4 to 5 dioptres of myopia or hypermetropia, the results are equivalent to those seen if pre-operative biometry is used.(1) However, a small percentage of patients will be found, whose post operative refraction is greater than four dioptres. Since this can be avoided, the use of a standard intraocular lens is unacceptable.

Estimation of implant power based on previous refraction, results in large residual refractive errors post-operatively. ${ }^{(2)}$ A number of theoretical formulae are in common usage. ${ }^{(3,4,5)}$ These formulae contain four assumed values; Corneal refractive index; aqueous and vitreous refractive index and post operative anterior chamber depth.

The technique of linear regression analysis, yielded the SRK ${ }^{\mathrm{TM}}$ formula devised by Sanders, Retzlaff and Kraff. ${ }^{6,7)}$ It has been shown to be more accurate than the theoretical formulae, even if these formulae contain a fudge factor. ${ }^{(8)}$

\section{Materials and Methods}

Fifty patients undergoing consecutive extracapsular cataract extraction and insertion of intraocular lens was studied. During the study one patient had bilateral cataract extractions performed and a total of 51 eyes were studied. The age range was from 44 to 89 years. There were 19 males and 31 females.

Pre-operatively a full ophthalmic examination was performed on all patients. Keratometry using a Topcon OM-4 keratometer was performed by either of the authors. One surgeon (MH-R) performed all the pre-operative biometry, using an Ultra Scan Digital A system, manufactured by Cooper Vision. This unit uses an applanation probe, mounted to a spring transducer, which prevents indentation of the cornea. The SRK ${ }^{\mathrm{TM}}$ formula was used to obtain the implant power for emmetropia, and a range of other post operative refractions. We used a lens power in each case, which slightly undercorrected the patients, post-operatively.

Correspondence to: Miss M. Hope-Ross, Research Unit, Royal Victoria Eye and Ear Hospital, Dublin 2.

Presented at a meeting of the Irish Ophthalmological Society. June 1987. 
Four surgeons performed the operative procedures. A standard extracapsular cataract extraction, using irrigation and aspiration, with insertion of a posterior chamber lens was performed.

Four different types of lenses were used, depending on the personal preference of the surgeon and the availability of lenses. In all cases, the A constant used was that specified by the manufacturers for that particular lens.

Post-operatively refraction was performed, between six and twelve weeks, by a number of different personnel, who were unaware of the expected post-operative refraction.

\section{Results}

Forty-eight eyes achieved a visual acuity of $6 / 12$ or better. Macular degeneration in 3 patients reduced the final visual acuity to $6 / 18$. in 2 patients and $6 / 24$ in one patient.

At the final refraction, the results were expressed as the spherical equivalent. The actual spherical equivalent was compared to the predicted refraction. The results were then expressed as the deviation of the actual refraction from the predicted refraction.

The average error was 0.9 dioptres. No error was greater than 3 dioptres. In 29 eyes, the error in the prediction of post operative refraction was under one dioptre, in 15 eyes between one and 2 dioptres and in 7 eyes between 2 and 3 dioptres. (See Table I.)

The range of lens power varied from 16 to 25 dioptres. (See Figure 1.) The lens power to produce emmetropia was calculated using the following formula. ${ }^{(9)}$ (See Figure 2.)

$$
\mathrm{De}=\mathrm{D}_{\mathrm{L}}+1.25 \mathrm{R}_{\mathrm{s}}
$$

Where $\quad D_{e}=$ Intraocular lens power to achieve emmetropia

$$
\begin{gathered}
\mathrm{D}_{\mathrm{L}}=\text { Dioptric power of the lens } \\
\text { actually implanted. } \\
\mathrm{R}_{\mathrm{s}}=\begin{array}{l}
\text { Spherical equivalent of the } \\
\text { spectacle refraction in } \\
\text { dioptres. }
\end{array}
\end{gathered}
$$

\section{Discussion}

The SRK ${ }^{\mathrm{TM}}$ formula is the most widely used formula in the calculation of intraocular lens power. It has been shown to be more accurate than the theoretical formulae, even if those are used with correction factors. ${ }^{(9)}$
SRK ${ }^{\mathrm{TM}}$ Formula:

$\mathrm{P}=\mathrm{A}-2.5 \mathrm{~L}-0.9 \mathrm{~K}$

$\mathrm{P}=$ Predicted implant power for emmetropia.

$\mathrm{A}=\mathrm{A}$ constant derived for each lens type and manufacturer.

$\mathrm{L}=$ Axial length ( $\mathrm{mm}$ )

$\mathrm{K}=$ Average keratometer reading (Dioptres).

In our study $55 \%$ of the patients were within one dioptre of the predicted refraction, $86 \%$ were within 2 dioptres. In $14 \%$ of the patients, the error in the prediction of post operative refraction was between 2 and 3 dioptres. No error was greater than 3 dioptres.

Table I Deviation of actual refraction from predicted refraction

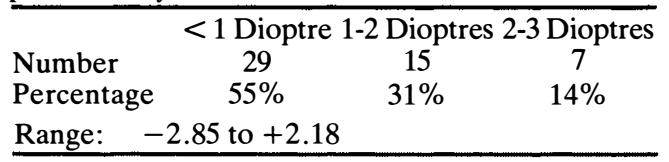

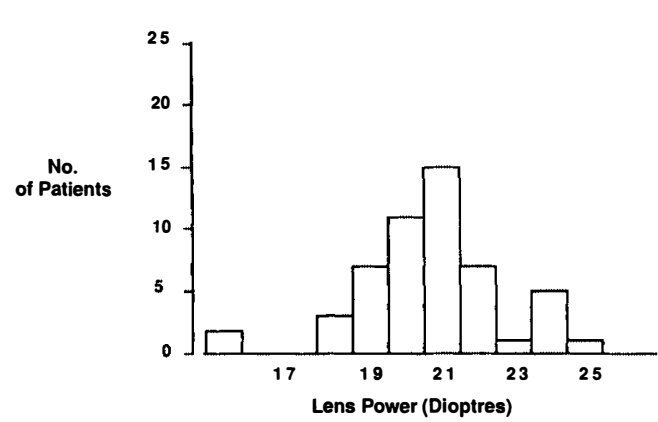

Fig. 1. Lens Power: Value of intraocular lens inserted.

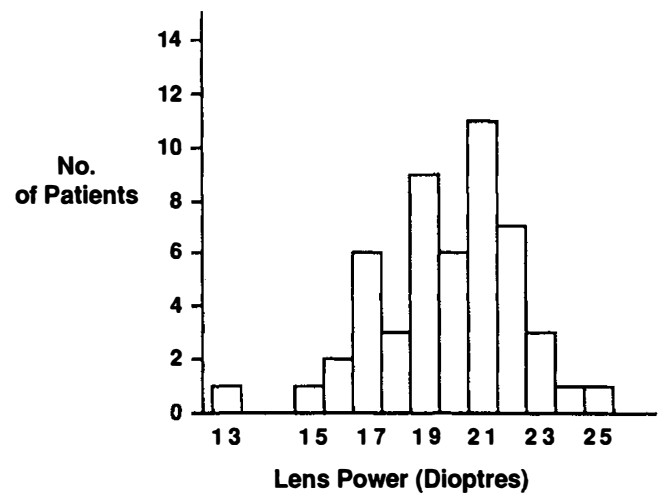

Fig. 2. Lens Power: Value of lenses required to produce emmetropia. 
There are a number of sources of error when using the SRK ${ }^{\mathrm{TM}}$ formula. The formula was derived primarily using data from offices with the Bausch and Lomb keratometer, which assumes a corneal refractive index of 1.3375. The Topcon OM-4 keratometer which we used also utilises a refractive index of 1.3375. Errors will result if a keratometer is being employed which uses a different corneal refractive index.

Accurate measurement of axial length is important, an error of $1 \mathrm{~mm}$ in the measurement of axial length, will cause a three dioptre error in implant power. Most ultrasound units are accurate to within $0.1 \mathrm{~mm}$, and errors in measurement are frequently due to observer error.

The A constant is specified by the manufacturers for each different type of lens. Utilising previous data, each surgeon should personalise the A constant for a given technique and lens.

No formula can as yet completely compensate for varying degrees of surgically induced astigmatism. Binkhorst observed a slight flattening of the cornea after surgery, and has added a correction to his formula to account for this. ${ }^{(5)}$

The measurement of implant power is difficult technically and a variation of as much as one dioptre may exist between manufacturers due to differences in technique. Lens mislabelling can also occur.

The optimum post operative refraction is a much debated point. With the absence of accommodation, hypermetropia is never desirable. Therefore, many clinicians aim to undercorrect their patients to avoid hypermetropia. A sligh amount of myopia over emmetropia has the advantage of an increased range of sharp vision and may allow reading without glasses. In our study we aimed to slightly undercorrect the patients.

Huber felt that a planned myopic astigmatism gave the patient a depth of focus, and rendered them spectacle independent. ${ }^{(10)}$ These patients have two far points, the emmetropic meridian gives a distorted but small image of objects located at infinity, the more myopic meridian gives a small distorted image of objects located at the second near (far) point.

Intraocular lens power calculation is a useful adjunct to the technique of extracapsular cataract extraction. We achieved satisfactory results using the $\mathrm{SRK}^{\mathrm{TM}}$ formula.

Note: Since this article was written, the SRK ${ }^{\mathrm{TM}}$ formula has been modified to improve accuracy. The new modified SRK II $^{\mathrm{TM}}$ formula, aims to improve accuracy in short eyes $(<22 \mathrm{~mm})$ and long eyes $(\geqslant 24.5 \mathrm{~mm})$.

\section{References}

${ }^{1}$ Singh K and Sommer A: Intraocular lens power calculations: A practical evaluation in normal subjects at the Wilmer Institute. Arch. Opthalmol 1987; 105: 1046-50.

2 Binkhorst RD: Pitfalls in the determination of intraocular lens power without ultrasound. Ophthal Surg. 1976; 7: 69-82.

${ }^{3}$ Colenbrander MD: Calculation of the power of an iris clip lens for distance vision. $\mathrm{Br} \mathrm{J}$ Ophthalmol 1973; 57: 735-40.

${ }^{4}$ Fyodorov SN, Galin MA, Linksz A: Calculation of the optical power of intraocular lenses. Invest. Ophth. 1975; 14: 625-8.

${ }^{5}$ Binkhorst RD: The optical design of intraocular lens implants. Ophthal Surg. 1975; 6: 17-31.

${ }^{6}$ Sanders DR and Kraff MC: Improvement of intraocular lens power calculation using empirical data. Am. Intra-Ocular Implant Soc. J. 1980; 6: 263-8.

${ }^{7}$ Retzlaff J: Posterior chamber implant power calculation: regression formulas. Am. IntraOcular Implant Soc. J. 1980; 6: 268-71.

${ }^{8}$ Sanders D, et al: Comparison of the accuracy of the Binkhorst, Colenbrander and $\mathrm{SRK}^{\mathrm{tm}}$ implant power prediction formulas. $\mathrm{Am}$. Intra-Ocular Implant Soc. J. 1981; 7: 337-40.

${ }^{9}$ Kraff MC, Sanders DR, Lieberman HL: Biometric analysis of intraocular lens power required to produce emmetropia: results of 450 implants. Am. Intra-Ocular Implant Soc. J. 1978; 4: 45-7.

${ }^{10}$ Huber C: Planned myopic astigmatism as a substitute for accommodation in pseudophakia. Am. Intra-Ocular Implant Soc. J. 1981; 7: 244-9. 